\title{
Pelatihan Kebersyukuran untuk Meningkatkan Sense of School Belonging Siswa SMP
}

\author{
Indah Nadzifah Hayati ${ }^{1} \mathcal{E}$ Budi Andayani \\ Fakultas Psikologi, Universitas Gadjah Mada
}

\begin{abstract}
Sense of School Belonging (SoSB) is a major requirement for students to function optimally at school. This study examined the effect of gratitude training on SoSB of Junior High School students. This study used a quasi-experimental untreated control group design with dependent pretest and posttest sample. There were 32 junior high school students participated in this study; divided into control group and experimental group. The result of the research data tested using Independent Samples t-Test showed the value of $t=3.023$, $(\mathbb{p}<0.05)$. It explained that the hypothesis is accepted, means the gratitude training can increase SoSB junior high school students significantly.
\end{abstract}

Keywords: gratitude; junior high school students; sense of school belonging

Abstrak. Sense of School Belonging ( $S o S B$ ) merupakan kebutuhan utama bagi siswa yang harus terpenuhi agar dapat berfungsi secara optimal di sekolah. Penelitian ini menguji pengaruh pelatihan kebersyukuran terhadap SoSB siswa SMP. Rancangan kuasi eksperimen, dengan disain the untreated control group, with dependent pre-test and post-test sample dipilih sebagai metode penelitan. Partisipan penelitian berjumlah 32 siswa, terbagi dalam kelompok kontrol dan eksperimen. Instrumen yang dipakai dalam penelitian adalah skala SoSB dan (modul) pelatihan kebersyukuran yang sudah tervalidasi. Hasil uji data penelitian menggunakan Independent Samples $t$-Test menunjukkan nilai $t=3,023,(\mathrm{p}<0,05)$. Hasil dari analisis tersebut menjelaskan bahwa hipotesis penelitian diterima, yaitu pelatihan kebersyukuran dapat meningkatkan SoSB pada siswa SMP secara signifikan.

Kata Kunci: rasa memiliki terhadap sekolah; siswa SMP; syukur

Rasa memiliki terhadap sekolah merupakan hal penting yang menjadi faktor protektif bagi remaja baik laki-laki maupun perempuan untuk mengurangi penggunaan obat-obatan, ketidakhadiran di sekolah, seksual dini, kekerasan, dan risiko ketidaksengajaan menyakiti diri

${ }^{1}$ Korespondensi mengenai artikel ini dapat dilakukan melalui: indah.nadzifah@mail.ugm.ac.id

${ }^{2}$ Atau melalui: anikoentjoro@ugm.ac.id
(Centers for Disease Control and Prevention, 2009).

satu SMP Negeri di Kabupaten Tulungagung pada tanggal 05 Oktober 2016 menunjukkan bahwa rasa memiliki terhadap sekolah pada siswa tergolong renda-h. Siswa mengeluh merasa kurang mendapatkan perhatian, dukungan, serta merasa diperlakukan dengan tidak baik dan tidak adil oleh guru. Selain itu, 
beberapa siswa mengeluh kurang memiliki kedekatan secara emosi dengan teman, karena merasa kurang diterima dan didukung oleh kelompok teman sebaya di sekolah. Kondisi ini pada akhirnya menyebabkan siswa menunjukkan antusiasme dan kehadiran yang rendah di sekolah. Konsep rasa memiliki terhadap sekolah dikenal dengan berbagai istilah seperti sense of school belonging (Goodenow, 1993), school connectedness (Jose, Ryan, \& Pryor, 2012), school identification (Wang \& Eccles, 2012), school attachment (Hallinan, 2008) dan sense of community (Osterman, 2000).

Goodenow (1993) menjelaskan bahwa Sense of School Belonging (SoSB) atau psychological membership in the school or classroom adalah kondisi yang terjadi ketika siswa merasa diterima secara personal, diperhatikan, dilibatkan dan didukung oleh orang lain di lingkungan sosial sekolah. Berbagai hasil penelitian dalam bidang pendidikan (Osterman, 2000; Wang \& Eccles, 2012, Lam, Chen, Zhang, \& Liang, 2015) menunjukkan kesimpulan yang sama, bahwa kebutuhan untuk memiliki (need for belonging) adalah kebutuhan paling penting bagi seluruh siswa agar dapat berfungsi secara baik dalam berbagai bidang di lingkungan pembelajaran. Merasa memiliki (feeling of belonging) dapat memberikan pengaruh yang langsung dan kuat bagi motivasi siswa, dan dapat memunculkan keyakinan bahwa siswa tidak hanya memiliki keterampilan individual namun juga tersedia sumber-sumber sosial untuk mengatasi hambatan atau kesulitan yang dihadapi (Goodenow, 1993), terutama pada siswa dari keluarga dengan sosial ekonomi rendah (Becker \& Luthar, 2002).

Siswa yang merasa ditolak di sekolah mereka merasa lelah, putus asa, bosan, dan tertekan, dan juga kurang merasa puas, kurang merasa tenang, dan nyaman ketika belajar, yang pada akhirnya beberapa tendensi ini dapat menurunkan performa akademik siswa (Lam et al., 2015). Selain itu, ketika rasa memiliki dalam diri siswa terhadap sekolah tidak dimiliki, siswa akan menunjukkan proses ketidakterlibatan secara bertahap, yang pada akhirnya mengarah kepada putus sekolah (Osterman, 2000).

Beberapa domain yang berkontribusi besar terhadap persepsi belonging pada siswa adalah: iklim kelas, hubungan antara siswa dengan guru, hubungan dengan teman sebaya atau persahabatan, dan juga dukungan dari orang tua atau keluarga. Iklim di lingkungan kelas yang baik adalah lingkungan yang menjadikan siswa merasa dilibatkan dan dapat berpendapat dengan leluasa (Goodenow, 1993), yang menekankan pada pembelajaran kooperatif, saling mendukung, peduli dan bekerja sama antar teman kelas sehingga dapat menjadikan siswa memiliki school belonging yang kuat (Anderman, 2002).

Guru, teman sebaya, dan orang tua merupakan kelompok yang memiliki hubungan dekat dengan siswa yang juga memengaruhi tingkat kepemilikian siswa terhadap sekolah (Uslu \& Gizir, 2016). Siswa yang memiliki kelompok teman sebaya dan guru yang mendukung akan merasa lebih puas dengan kerja sekolah, merasa dihargai, percaya diri, dan menunjukkan sikap positif terhadap sekolah (Pittman \& Richmond, 2008). 
Selain itu dengan keterlibatan dari keluarga, memudahkan guru untuk mendapatkan informasi dan mengkomunikasikan perkembangan siswa dengan cara yang efektif, yang kemudian dapat menjadikan siswa merasa diterima oleh guru (Stewart, 2008).

Peneliti menemukan bahwa aspek internal yang menjadi penyebab permasalahan sense of school belonging siswa adalah adanya persepsi negatif terhadap sekolah yang kemudian termanifestasi dalam perilaku. Trower, Casey, dan Dryden (2008) menjelaskan bahwa interpretasi terhadap pengalaman merupakan hipotesis atau mengarah kepada sebuah keyakinan semata daripada fakta, dan hal tersebut dapat benar namun dapat pula salah. Ketika seseorang memegang teguh keyakinan yang tidak realistis dan negatif mengenai dirinya atau pengalamannya, maka akan terjadi gangguan emosi dan akhirnya memengaruhi tindakan seseorang.

Diebel (2016) dalam penelitiannya menemukan bahwa siswa Sekolah Dasar yang mendapatkan intervensi berupa buku harian syukur (gratitude diaries) selama empat minggu memiliki rasa syukur dan rasa memiliki terhadap sekolah (sense of school belonging) yang lebih tinggi dibandingkan dengan kelompok yang diberikan intervensi berupa menulis kejadian sehari-hari di sekolah. Peningkatan skor syukur berhubungan positif dengan peningkatan skor sense of school belonging. Syukur meningkatkan kesadaran mengenai perilaku pro-sosial dan positif dari staff dan teman sebaya, meningkatkan persepsi didukung oleh orang lain di sekolah, penguatan persahabatan oleh teman sebaya dan apresiasi perilaku positif dari staff sekolah (Diebel, 2016).

Peterson dan Seligman (2004) mendefinisikan syukur sebagai rasa berterimakasih dan bahagia sebagai respon penerimaan karunia, baik karunia tersebut merupakan keuntungan yang diterima dari orang lain maupun momen kedamaian yang ditimbulkan oleh keindahan alamiah. Rasa syukur timbul dari sebuah hubungan ketika seorang mengetahui bahwa Ia menerima kebaikan yang bernilai dari orang lain. Syukur seperti emosi sosial lainnya, berfungsi untuk meregulasi hubungan, menguatkan dan mengeratkan mereka (Algoe \& Stanton dalam Watkins, 2014).

Syukur adalah sebuah kesadaran dan secara kognitif memengaruhi emosi (Watkins, 2014). Syukur dapat terjadi dengan adanya proses penilaian kognitif dimana kondisi ini dikarakteristikkan sebagai "The Recognitions of Gartitude" Watkins (2014). Rekognisi adalah mengetahui atau mengapresiasi kebenaran, atau identifikasi seseorang, sesuatu, atau situasi karena seseorang telah merasakan sebelumnya.

Watkins (2014) menyebutkan tiga komponen dasar syukur yang disebut sebagai "three pillars of gratitude", yang terdiri dari adanya sebuah rasa keberlimpahan yang kuat (a sense of abundance), apresiasi terhadap kenikmatankenikmatan sederhana (an appreciation of simple pleasures), dan adanya apresiasi sosial (appreciation for others).

Mukhlis (2015) membuktikan bahwa intervensi kebersyukuran melalui pelatihan bagi remaja dapat membantu 
siswa remaja mendapatkan tambahan pengetahuan mengenai cara bersyukur dan bagaimana mengambil hal-hal positif dari sebuah pengalaman baik yang menyenangkan maupun yang tidak menyenangkan dalam hidup.

Penelitian ini menggunakan modul pelatihan kebersyukuran yang disusun oleh Mukhlis (2015), kemudian dimodifikasi oleh peneliti sesuai dengan tujuan penelitian. Modul pelatihan kebersyukuran pada penelitian ini berisi empat langkah syukur menurut Watkins (2014) yang terdiri dari recounting, reflection, reappraisal, dan expressing. Siswa diharapkan mengalami peningkatan sense of school belonging setelah mendapatkan perlakuan berupa pelatihan kebersyukuran dengan empat langah syukur ini. Dinamika pengaruh pelatihan kebersyukuran terhadap peningkatan sense of school belonging dijelaskan dalam paragraf berikut.

Tahap recounting menumbuhkan kesadaran siswa mengenai berbagai kebaikan dan kontribusi-kontribusi yang datang dari orang-orang di sekolah, sekecil apapun kebaikan atau nikmat tersebut, Watkins (2014) menyebutnya sebagai appreciation of simple pleasure. Watkins (2014) menyimpulkan bahwa perlakuan menghitung nikmat melatih orang untuk lebih menyadari mengenai hal-hal baik yang ada dalam kehidupan mereka, dan hal tersebut juga melatih individu untuk memproses kebaikan-kebaikan yang mereka peroleh dalam sebuah cara syukur. Kesadaran dan rekognisi syukur ini dapat membantu siswa untuk lebih berfokus kepada hal-hal positif yang diterima dari teman dan guru, serta dari berbagai situasi sosial yang dialami di sekolah, sehingga dapat menimbulkan persepsi yang lebih positif terhadap sekolah yang mengarahkan kepada meningkatnya sense of school belonging.

Tahap reflection mengajarkan siswa untuk merefleksikan nikmat dan kebaikan yang diterima di sekolah, kemudian mentransformasikan penghargaan atas nikmat dan kebaikan yang diterima di sekolah menjadi rasa syukur. Refleksi pada tahap ini dapat membantu siswa untuk lebih merasakan manfaat dari kebaikan yang datang dari orang-orang yang ada di sekolah melalui penilaian kembali dan penyesuaian. Hal ini sesuai pendapat Watkins (2014) bahwa latihan refleksi membantu seseorang untuk merenungkan kenikmatan dengan sebuah cara penyesuaian. Selain itu refleksi kebaikan ini dapat meningkatkan penilaian atau evaluasi menyenangkan atas orang lain (Hedstrom dalam Emmons \& McCullough, 2003).

Tahap ketiga dalam pelatihan kebersyukuran adalah "reapprasial", yang mengajarkan kepada siswa untuk memahami konsep bahwa selalu ada hikmah dari setiap pengalaman yang tidak menyenangkan yang dialami di sekolah. Individu yang memiliki kecenderungan syukur akan lebih menggunakan penilaian kembali yang lebih positif (poistive reframing) sebagai sebuah cara dalam menginterpretasi peristiwa negatif, sehingga mereka dapat melihat hidup dengan lebih teratur, bermakna, dan dapat dipahami (Lambert, Fincham, Graham, \& Stillman , 2009). Lebih lanjut Watkins, Cruz, Holben, \& Kolts (2008) memaparkan bahwa grateful reappraisal membantu 
individu menutup memori menyakitkan, yang menurunkan dampak negatif dan gangguan yang timbul dari memori tersebut.

Expressing merupakan tahap keempat yang dilatih dalam pelatihan. Siswa pada tahap ini mengungkapkan apresiasi atau rasa berterimakasih secara langsung kepada orang-orang yang berjasa di sekolah melalui sebuah surat. Tahap ini merupakan bentuk pembelajaran untuk mengaplikasikan prinsip "appreciation of others" yaitu bahwa orang yang bersyukur merasa penting untuk mengekspresikan apresiasi kepada orang yang berkontribusi dalam kehidupan mereka. Mengekspresikan syukur kepada seorang teman meningkatkan rasa hormat terhadap teman, membuat partisipan lebih nyaman dalam menyuarakan pentingnya persahabatan kepada teman (Lambert et al, 2009) dan meningkatkan persepsi terhadap kekuatan hubungan dalam persahabatan (Lambert, Clark, Graham, Durtschi, \& Fincham, in press).

Berdasarkan beberapa kajian dari berbagai penelitian sebelumnya, pengamatan terhadap fenomena, serta informasi yang diperoleh dari lapangan, menghasilkan gagasan peneliti untuk melihat validitas isi modul kebersyukuran yang dimodifikasi oleh peneliti, dan kemudian menguji bagaimana pengaruh pelatihan kebersyukuran terhadap perubahan sense of school belonging pada siswa SMP.

\section{Metode}

\section{Partisipan penelitian}

Partisipan penelitian berjumlah 32 siswa yang berasal dari SMP A dan SMP B di Kabupaten Tulungagung. Partisipan terbagi ke dalam dua kelompok, yaitu kelompok eksperimen sebanyak 19 partisipan berasal dari sekolah A, dan kelompok kontrol sebanyak 13 partisipan berasal dari SMP B. Partisipan merupakan siswa yang duduk di kelas VIII, memiliki skor skala sense of school belonging dalam kategori rendah hingga sedang (dengan rentang total skor 32 hingga 57), dan bersedia terlibat dalam penelitian yang dibuktikan dengan kesediaan untuk menandatangani informed concent.

Instrumen penelitian

Skala Sense of School Belonging

Skala yang digunakan untuk mengukur Sense of School Belonging pada partisipan adalah skala yang diadaptasi oleh peneliti dari Psychological Sense of School Membership Scale (PSSM; Goodenow, 1993). Hasil validasi oleh ahli menunjukkan bahwa skala ini memiliki koefisien Aiken's V sebesar 0,656 hingga 0,828. Angka di atas 0,5 tersebut menunjukkan bahwa validitas isi pada tiap sesi modul terbilang baik. Skala ini berjumlah 17 butir, dengan koefisien reliabilitas alpha cronbach sebesar 0,825 .

Skala syukur di sekolah

Instrumen untuk mengukur kebersyukuran pada penelitian ini menggunakan skala yang dimodifikasi oleh peneliti dengan mengacu kepada Gratitude Resentment and Appreciation Test (GRAT) Short Form (Thomas \& Watkins, 
2003). Alat ukur ini dimodifikasi oleh peneliti sesuai tujuan penelitian dengan memfokuskan syukur kepada pengalaman siswa di sekolah. Nilai koefisien Aiken's V dari ahli berkisar antara 0,547 hingga 0,797. Butir pernyataan dalam skala ini berjumlah 14, dengan koefisien reliabilitas alpha cronbach sebesar 0,743 .

\section{Desain penelitian}

Penelitian ini merupakan penelitan kuasi eksperimen dengan desain the untreated control group design with dependent pre-test and post-test sample (Shadish, Cook, \& Campbell, 2002). Penempatan subjek pada kelompok kontrol dan kelompok eksperimen dilakukan secara tidak acak (non-random assignment; Shadish, et al., 2002). Pengukuran pada kelompok eksperimen dilakukan sebelum dan sesudah perlakuan diberikan. Pada kelompok kontrol, pengukuran diberikan sebanyak dua kali tanpa memberikan perlakuan.

\section{Perlakuan}

Perlakuan diberikan dalam bentuk pelatihan dengan mengacu kepada modul pelatihan kebersyukuran yang disusun oleh Mukhlis (2015), kemudian dimodifikasi, divalidasi dan dujicoba oleh peneliti. Modifikasi modul dilakukan dengan melakukan perubahan dalam instruksi, memberikan tambahan aktivitas dan media berupa menulis pada daun syukur, games dan tayangan video untuk lebih menarik minat partisipan, serta memberikan tambahan sesi, yaitu sesi opening dan review.
Validasi modul pelatihan kebersyukuran

Peneliti menguji validitas isi modul dengan meminta penilaian kepada enam orang yang memiliki keahlian dalam bidang penyusunan modul, psikologi positif, perkembangan remaja, trainer dan juga psikolog.

Hasil penilaian validitas isi modul oleh ahli menunjukkan nilai koefisien Aiken's V yang diperoleh pada modul ini yakni pada rentang 0,75 hingga 0,875. Penilaian dan masukan dari ahli dijadikan acuan dalam memodifikasi modul untuk diujicoba kepada 10 siswa SMP kelas VIII. Partisipan uji coba modul pelatihan memberikan penilaian dalam bentuk angket dengan rentang angka 1 hingga 4 . Adapun rata-rata penilaian yang diberikan adalah: materi $=3,9$; media (games, film, dan tayangan power point $)=3,43$; tugas dan buku tugas $=3,45$; kemanfaatan pelatihan $=3,9$; aktifitas pelatihan secara umum $=3,7$; trainer $=3,6$. Penilaian yang diberikan oleh ahli dan oleh peserta pelatihan uji coba modul menunjukkan angka yang cukup baik, sehingga dapat disimpulkan bahwa modul pelatihan ini layak digunakan dalam penelitian.

\section{Analisis Data}

Data hasil penelitian dianalisis dengan menggunakan independent sample t-test dengan menggunakan bantuan SPSS 17. for Windows. Uji ini digunakan untuk melihat perbedaan rerata gain score (skor post-test dikurangi skor pre-test) skala sense of school belonging antara kelompok kontrol dan kelompok eksperimen. 


\section{Hasil}

Penelitian pada kelompok eksperimen dan kelompok kontrol menunjukkan data deskriptif yang dijelaskan dalam Tabel 1. Rerata skor pre-test sense of school belonging pada kelompok kontrol adalah 52,308, sedangkan pada kelompok eksperimen adalah sebesar 53,105. Skor pre-test ini diukur perbedaannya untuk memastikan bahwa kedua kelompok berada dalam kondisi setara sebelum diberikan perlakuan. Uji beda pada skor pre-test menggunakan independent sample t-test menunjukkan nilai t-hitung $=0,483$ $(p>0,05)$, yang berarti bahwa tidak ada perbedaan kondisi sense of school belonging antara kelompok kontrol dan kelompok eksperimen sebelum diberikan perlakuan.

Data hasil penelitian pada kelompok eksperimen dan kelompok kontrol dianalisis dengan menggunakan independent sample t-test. Hipotesis yang diajukan dalam penelitian ini adalah ada perbedaan gain score (skor posttest dikurangi skor pretest) skala sense of school belonging yang signifikan antara kelompok eksperimen yang diberikan pelatihan kebersyukuran dengan kelompok kontrol yang tidak diberikan perlakuan, dimana gain score kelompok eksperimen lebih tinggi dibandingkan kelompok kontrol.
Hasil uji hipotesis menggunakan independent sample t-test menunjukkan nilai $t=3,023(p<0,05)$. Hasil ini menjelaskan bahwa terdapat perbedaan gain score sense of school belonging yang signifikan antara kelompok kontrol dan kelompok eksperimen. Rerata gain score pada kelompok eksperimen adalah 11,47 sedangkan pada kelompok kontrol adalah 4,62. Angka ini menunjukkan bahwa rerata gain score kelompok eskperimen lebih tinggi dibandingkan dengan rerata gain score pada kelompok kontrol.

Pengukuran dampak perlakuan berdasarkan pada formula Cohen's $d$ (Becker, 2000) menunjukkan nilai $d=1,125$. Nilai $d>0,8$ masuk dalam kategori ukuran dampak yang besar (Cohen, 1992). Hal ini dapat dimaknai bahwa pelatihan kebersyukuran memberikan perbedaan yang besar pada sense of school belonging antara kelompok yang diberikan perlakuan dengan yang tidak diberikan perlakuan.

Data skor cek manipulasi pada skala syukur sebelum dan setelah dilakukan pelatihan pada kelompok eksperimen dianalisis dengan paired sample t-test.

Hasil analisis menunjukkan rerata skor kecenderungan syukur sebelum diberikan pelatihan kebersyukuran adalah 64,05, sedangkan rata-rata skor syukur

Tabel 1.

Data statistik deskriptif penelitian

\begin{tabular}{lccccc}
\hline Kelompok & $\begin{array}{c}\text { Sense of School Belonging } \\
\text { Pre-Test }\end{array}$ & Post-Test & N & Laki-laki & Perempuan \\
\hline \hline Kontrol & 52,308 & 56,923 & 13 & 6 & 7 \\
\hline Eksperimen & 53,105 & 64,579 & 19 & 16 & 3 \\
\hline Jumlah & & & 32 & 22 & 10
\end{tabular}


sesudah pelatihan adalah 71,58. Berdasarkan uji analisis tersebut diketahui nilai $\mathrm{t}$ hitung $=-6,885 \quad(\mathrm{p}<0,01)$. Hasil penghitungan menunjukkan terdapat perbedaan skor syukur yang signifikan pada kelompok eksperimen sebelum dan setelah pelatihan kebersyukuran diberikan, dengan rerata skor post-test lebih besar dibandingkan dengan skor pre-test. Peningkatan rerata skor yang signifikan menunjukkan bahwa perlakuan yang diberikan dalam penelitian berhasil dilaksanakan.

Analisis tambahan menunjukkan bahwa sumbangan efektif pelatihan kebersyukuran terhadap peningkatan $S o S B$ adalah sebesar $40 \%$. Sumbangan efektif berasal dari masing-masing komponen aktivitas pelatihan yakni; "recounting" sebesar 28,54 \%, "reflection" 11,16\%, "reappraisal" sebesar 0,20\%, sedangkan "expression" memberikan sumbangan terhadap sense of belonging dalam porsi yang lebih kecil yakni sebesar 0,10\%.

\section{Diskusi}

Pengujian hipotesis penelitian menunjukkan bahwa gain score sense of school belonging antara kelompok eksperimen dan kelompok kontrol berbeda secara signifikan. Hasil pengujian tersebut menjelaskan bahwa kelompok eksperimen yang diberikan pelatihan kebersyukuran mengalami peningkatan skor sense of school belonging yang lebih tinggi, dibandingkan dengan kelompok kontrol yang tidak diberikan pelatihan kebersyukuran.

Hasil ini mendukung penelitian yang dilakukan oleh Diebel (2016) tentang pengaruh buku harian syukur (gratitude diary) terhadap peningkatan sense of school belonging pada siswa Sekolah Dasar (SD). Diebel (2016) menjelaskan bahwa partisipan yang menyelesaikan intervensi syukur menunjukkan peningkatan kepemilikan terhadap sekolah (school belonging) dan syukur, dibandingkan dengan kelompok kontrol, dan peningkatan syukur berkorelasi positif dengan peningkatan sense of school belonging.

Uji ukuran dampak perlakuan (effect size) menunjukkan bahwa perbedaan rerata gain score sense of school belonging kelompok eksperimen dengan kelompok kontrol cukup besar dengan nilai $d=1,125$. Angka ini menjelaskan pula bahwa skor sense of school belonging antara kelompok yang diberikan perlakuan berupa pelatihan kebersyukuran dengan yang tidak diberikan perlakuan sangat jauh berbeda, dimana kelompok eksperimen memiliki skor yang jauh lebih tinggi dibandingkan kelompok kontrol.

Pelatihan kebersyukuran memberikan kontribusi terhadap peningkatan sense of school belonging pada siswa sebesar 40\%. Peningkatan sense of school belonging dalam penelitian ini sebagian besar dipengaruhi oleh aktivitas "recouting" dengan prosentase 28,54\%. Aktivitas ini mengajarkan prinsip "appreciation of simple pleasures" di mana seorang yang bersyukur memberikan apresiasi terhadap hal-hal sederhana dalam hidup mereka, sebagaimana mereka mengapresiasi hal-hal besar yang mereka peroleh. Intervensi recounting telah digunakan pada 7 dari 12 penelitian intervensi syukur. Sejalan dengan penelitian ini, pada penelitian lain 
partisipan sering melaporkan bahwa teknik ini menyenangkan dan menguatkan diri (Seligman, Steen, Park, \& Peterson, 2005). Recounting membantu siswa melihat kondisi dan peristiwa di sekolah dengan cara pandang yang lebih apresiatif dan berterimakasih (Froh, Sefick, \& Emmons, 2008). Beberapa nikmat dan kebaikan yang diapresiasi siswa diantaranya adalah dapat diterima di sekolah, memiliki banyak teman, diterima dengan baik oleh guru saat pelajaran, mendapatkan nilai pelajaran yang baik, dilibatkan dalam perlombaan olah raga oleh guru, dibelikan sesuatu oleh teman, mendapatkan ilmu, memperoleh nilai ulangan yang lebih bagus, dan terpilih dalam pelatihan kebersyukuran.

Sesi refleksi memberikan kontribusi sebesar $11,16 \%$ terhadap peningkatan skor sense of belonging partisipan. Penemuan ini semakin mempertegas pendapat bahwa refleksi syukur dapat menghasilkan peningkatan signifikan pada afek positif (positive affect; Watkins, 2014) dan dapat meningkatkan penilaian atau evaluasi menyenangkan partisipan terhadap kontribusi orang lain di sekolah (Emmons \& McCullough, 2003) sehingga berkontribusi pada peningkatan sense of school belonging.

Reapprasial pada sesi ketiga memberikan sumbangsih sebesar 0,20\% terhadap sense of belonging. Penemuan ini menunjukkan bahwa dengan memberikan penilaian kembali dengan cara yang lebih positif (positive reframing) terhadap peristiwa negatif yang dialami, terutama di sekolah, dapat membantu partisipan untuk melihat sekolah sebagai lingkungan yang bermakna dan dapat difahami
(Lambert et al., 2009). Partisipan menuliskan berbagai peristiwa tidak menyenangkan yang dialami di sekolah, (seperti "mendapatkan hukuman karena terlambat", "diejek oleh teman", dan "dimarahi oleh guru"), menjadi sebuah penilaian positif dimana hal-hal tersebut memberikan hikmah (seperti "memotivasi agar lebih datang tepat waktu", "menjadikan lebih mengevaluasi diri", dan juga "mendorong siswa agar bisa menjadi lebih baik lagi").

Tahap expressing pada pelatihan kebersyukuran dapat meningkatkan rasa hormat terhadap teman, membuat partisipan lebih nyaman dalam menyuarakan pentingnya persahabatan kepada teman (Lambert et al, 2009) dan meningkatkan persepsi terhadap kekuatan hubungan dalam persahabatan (Lambert, et al., in press). Hasil dari penghitungan sumbangan efektif pelatihan kebersyukuran menunjukkan bahwa expressing memberikan kontribusi efektivitas yang lebih kecil dibandingkan dengan aktivitas lain dalam pelatihan kebersyukuran ini, dengan persentase sebesar $0,10 \%$.

Beberapa subjek pada kelompok kontrol mengalami peningkatan skor sense of school belonging. Rerata skor sense of school belonging meningkat dari yang semula 52,3 menjadi 56,9. Pengujian data menggunakan paired sample t-test, didapatkan kesimpulan bahwa terdapat perubahan yang signifikan pada kelompok kontrol yang tidak diberikan perlakuan. Kondisi ini dapat disebabkan oleh rentang waktu pengukuran pada kelompok kontrol yang lebih lama dibandingkan dengan kelompok eksperimen. Hal ini 
menjadi salah satu faktor yang dapat mengancam validitas internal penelitian eksperimen berupa maturation. Subjek penelitian terutama kelompok kontrol, pada kondisi ini memiliki kesempatan yang lebih banyak untuk mengalami berbagai perubahan atau kematangan pada aspek psikologis yang memengaruhi sense of school belonging. Namun, secara keseluruhan hasil ini tidak memengaruhi pengambilan keputusan hipotesis penelitian, karena pengujian hipotesis menggunakan independet sample t-test.

\section{Kesimpulan}

Kesimpulan dari hasil penelitian ini adalah bahwa pelatihan kebersyukuran yang terdiri dari aktivitas recounting, reflection, reappraisal, dan expressing, secara signifikan dapat meningkatkan sense of school belonging. Hal ini terlihat dari adanya perbedaan gain score antara kedua kelompok penelitian, dimana gain score pada kelompok eksperimen lebih tinggi dari pada gain score pada kelompok kontrol. Pelatihan kebersyukuran memberikan kontribusi sebesar 40\% terhadap peningkatan sense of school belonging siswa, dimana sumbangan terbesar diberikan berasal dari aktivitas "recounting", dengan presentase sebesar $28,54 \%$.

\section{Saran}

Beberapa hal yang dapat direkomendasikan untuk peneliti selanjutnya adalah sebagai berikut: Pertama, peneliti selanjutnya dapat lebih memerhatikan kontrol terhadap ancaman validitas internal, terutama pada kesetaraan rentang waktu pengukuran antara kelompok kontrol dan kelompok eksperimen. Hal ini dapat memengaruhi perubahan skor, diakibatkan oleh adanya kematangan pada salah satu kelompok partisipan penelitian.

Kedua, peneliti selanjutnya dapat melakukan penelitian serupa namun dengan jumlah subjek yang lebih besar dan juga dilakukan random assignment. Ketiga, partisipan penelitian ini didominasi oleh siswa dengan skor sense of school belonging dalam taraf sedang, sehingga peneliti selanjutnya dapat menguji pengaruh pelatihan kebersyukuran terhadap subjek dengan skor sense of school belonging rendah supaya manfaat dari pelatihan ini lebih terlihat. Keempat, penelitian ini belum menguji efektivitas pelatihan setelah dilakukan post-test, sehingga untuk mengetahui sampai berapa lama pelatihan kebersyukuran memberikan pengaruh bagi sense of school belonging pada partisipan, maka perlu dilakukan pengukuran follow up.

\section{Kepustakaan}

Anderman, E. M. (2002). School effects on psychological outcomes during adolescence. Journal of Educational Psychology, 94, 795 - 809.

Becker, B. E., \& Luthar, S. S. (2002). Socialemotional factors affecting achievement outcomes among disadvantaged students: Closing the achievement gap. Educational Psychologist, 37(4), 197-214. 
Becker, L. A. Effect size (EF). (2000). http://web.uccs.edu/lbecker/Psy590/e s.htm.

Centers for disease control and prevention. (2009). School connectedness: Strategies for increasing protective factors among youth. Atlanta, GA: U.S. Department of Health and Human Service.

Cohen, J. (1992). A power primer. Psychological Bulletin, 112(1), 155-159.

Diebel, T. (2016). Establishing the effectiveness of a gratitude diary intervention on children's sense of school belonging. Doctoral dissertation in Educational Psychology. England: Unversity of Southampton.

Emmons, R. A., \& McCullough, M. E. (2003). Counting blessings versus burdens: An Empirical investigation of gratitude and subjective wellbeing in daily life. Journal of Personality and Social Psychology, 84(2), 377-389. doi: 10.1037/00223514.84.2.377.

Froh, J. J., Sefick, W. J., \& Emmons, R. A. (2008). Counting blessings in early adolescents: An experimental study of gratitude and subjective wellbeing. Journal of School Psychology, 46, 213-233. doi: 10.1016/j.jsp.2007.03.005.

Goodenow, C. (1993). The psychological sense of school membership among adolescents: Scale development and educational correlates. Psychology in the schools, 30, 70-90. doi: 10.1002/15206807(199301)30:1<79::AIDPITS2310300113>3.0.CO;2-X.

Hallinan, M. T. (2008). Teacher influences on students' attachment to school.
Sociology of Education, 81, 271-283. doi: 10.1177/003804070808100303.

Jose, P. E., Ryan, N., \& Pryor, J. (2012). Does social connectedness promote a greater sense of well-being in adolescence over time? Journal of Research on Adolescence, 22, 235-251.

Lam, U. F., Chen, W. W., Zhang, J., \& Liang, T. (2015). It feels good to learn where i belong: School belonging, academic emotions, and academic achievement in adolescents. School Psychology International, 36(4), 393409.

doi: 10.1177/0143034315589649.

Lambert, N. M., Clark, M. S., Graham, S. M., Durtschi, J. A., \& Fincham, F. D. (in press). Gratitude and communal strengths. Psychological Science.

Lambert, N. M., Fincham, F. D., Graham, S. M., \& Stillman, T. F. (2009). A changed perspective: How gratitude can affect sense of coherence through positive reframing. The Journal of Positive Psychology. 4(6), 461-470. doi: 10.1080/17439760903157182.

Mukhlis, A. (2015). Pelatihan kebersyukuran untuk menurunkan kecemasan menghadapi ujian nasional pada siswa $S M A$. Tesis tidak dipublikasikan. Universitas Gadjah Mada, Yogyakarta.

Osterman, K. F. (2000). Students' need for belonging in the school community. Review of Educational Research, 70(3), 323-367.

Peterson, C \& Seligman, M. E. P. (2004). Character, strenghts, and virtues: $A$ handbook $\mathcal{E}$ classification. NewYork: Oxford University press. 
Pittman, L. D., \& Richmond, A. (2008). University belonging, friendship quality and psychological adjustment during the transition to college. The Journal of Experimental Education, 76, 343-361.

Shadish, W. R., Cook, T. D., \& Campbell, D. T. (2002). Experimental and quasiexperimental designs for generalized causal inference. New York: Houghton Mifflin Company.

Seligman, M. E. P., Steen, T. A., Park, N., \& Peterson, C. (2005). Positive psychology progress: Empirical validation of interventions. American Psychologist, 60, 410-421.

Stewart, B. E. (2008). School structural characteristics, student effort, peer associations and parental involvement. Education and Urban Society, 40, 179-200.

Thomas, M., \& Watkins, P. (2003). Measuring the grateful trait: Development of the revised GRAT. Presentation to the 83rd Annual Convention of the Western Psychological Association, Vancouver, British Columbia, Canada.

Trower, P., Casey, A., and Dryden, W. (2009). Cognitive-behavioural counselling in action. London: SAGE Publications.

Uslu, F., \& Gizir, S. (2016). School belonging of adolescents: The role of teacher-student relationships, peer relationships and family involvement. Educational Sciences: Theory \& Practice, 16, 21-40. doi: 10.12738/estp.2017.1.0104
Wang M., \& Eccles, J. S. (2012). Social support matters: Longitudinal effects of social support on three dimensions of school engagement from middle to high school. Child Development, 83, 877-895.

Watkins, P. C., Cruz, L., Holben, H., \& Kolts, R. L. (2008). Taking care of business? Grateful processing of unpleasant memories. The Journal of Positive Psychology, 3, 87-99.

Watkins, P. C. (2014). Gratitude and the good life: Toward a psychology of appreciation. New York: Springer. 